\title{
Iodine Content of Processed Foods and Condiments Sampled in China, 2017-2019
}

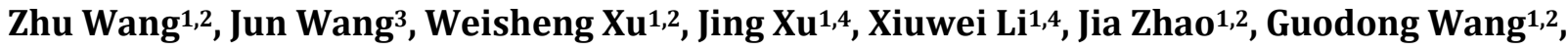 \\ Xiaoguang Yang1,2
}

\author{
${ }^{1}$ National Institute for Nutrition and Health, Chinese Center for Disease Control and Prevention, Beijing, China \\ ${ }^{2}$ Key Laboratory of Trace Element Nutrition, National Health Commission, Beijing, China \\ ${ }^{3}$ Central Laboratory of Shenzhen Center for Chronic Disease Control, Shenzhen, China \\ ${ }^{4}$ National Reference Laboratory for Iodine Deficiency Disorders, Beijing, China \\ Email: xgyangcdc@163.com
}

How to cite this paper: Wang, Z., Wang, J., Xu, W.S., Xu, J., Li, X.W., Zhao, J., Wang, G.D. and Yang, X.G. (2021) Iodine Content of Processed Foods and Condiments Sampled in China, 2017-2019. Food and Nutrition Sciences, 12, 1217-1231. https://doi.org/10.4236/fns.2021.1212089

Received: January 5, 2021

Accepted: December 18, 2021

Published: December 21, 2021

Copyright $\odot 2021$ by author(s) and Scientific Research Publishing Inc. This work is licensed under the Creative Commons Attribution International License (CC BY 4.0).

http://creativecommons.org/licenses/by/4.0/

\begin{abstract}
Introduction: Facing the challenge of increasing consumption of processed foods in China, along with the demand for salt reduction, and dynamic adjustment of universal salt iodization (USI) policy, it is necessary to timely evaluate the distribution of iodine content in processed foods and condiments, so as to provide more accurate data for population dietary iodine intake assessment. Methods: From markets in 6 cities and e-commerce platforms, cereal, tuber, legume, meat, fish, egg, and dairy products, and condiments, consumed by volunteers who attended in iodine intake investigation, and top selling products in particular with well-noted brands were preferentially sampled during 2017 to 2019. After being mixed and homogenized, each sample was detected by ICP-MS method. The range and medium of iodine content in each type of product were given. Results: After merging samples with close value in the same style of the same brand, and screening out samples with no added salt or low sodium content $(\leq 120 \mathrm{mg} / 100 \mathrm{~g})$, total 725 data were sub-grouped and analyzed. In comparison with the $95^{\text {th }}$ percentile of the iodine distribution in relative nature source, assessed by our previous study, nearly $77 \%$ of products made from grains, potatoes, beans, nuts, livestock and poultry meat were presumed to be processed with iodized salt. In somewhat, related with sodium value marked on food labeling, the median iodine ranged from $1.1 \mathrm{mg} / 100 \mathrm{~g}$ to $149 \mathrm{mg} / 100 \mathrm{~g}$. The variation of iodine in egg, milk and fish made products, and seaweed or with seaweed products was greatly affected by the background of ingredients, the median content most floated between $12.8 \mathrm{mg} / 100 \mathrm{~g}$ and 86.8 $\mathrm{mg} / 100 \mathrm{~g}$, even up to $1800 \mathrm{mg} / 100 \mathrm{~g}$ in seasoned seaweed. Based on the frequency of iodine digital and the ratio of iodine to sodium, it was speculated that nearly $90 \%$ of soy sauce and $73.5 \%$ of other seasonings like vinegar, sauce,
\end{abstract}


paste, etc., were not added iodized salt, with overall median iodine $4.0 \mathrm{mg} / 100 \mathrm{~g}$ and $12 \mathrm{mg} / 100 \mathrm{~g}$ respectively. Conclusion: Using iodized salt in processed foods is an approach of USI police. Affected by the nature backgrounds of ingredients composed, the amount of salt used, and the regulated fortification level, iodine content in each kind of product varied largely. It's important to establish a monitoring system in processed foods, as well as fortification salt, to control the benefit and risk of iodine health.

\section{Keywords}

Iodine Content, Universal Salt Iodization, Processed Food, Edible Salt, Database

\section{Introduction}

Iodine is an essential nutrient for human health, especially for women and children. Iodine deficiency causes a spectrum of growth, developmental and functional morbidity across the life course, termed iodine deficiency disorders (IDD). Elimination IDD is therefore a global health target for World Health Organization.

Initiation of universal salt iodization (USI) is recommended as a safe, costeffective and sustainable strategy [1] [2]. In order to achieve adequate iodine intake, iodized salt is asked to be used not only in household cooking, but also in manufacturing processed foods in many countries of Asia [3].

Iodine deficiency has been recognized as a severe health problem in China since 1930s, according to data collected before 1997, the incidence of IDD in children and pregnant women in areas of iodine deficiency may be up to $50 \%$, that occurred nearly in all provinces [4] [5]. So, China is one of the earliest countries to respond to USI. Mandatory salt iodization started in 1994, when the Regulation on Salt Iodization to Eliminate IDD was issued by the State Council [6]. Taking into account inevitable iodine loss during storage, the initial iodized level in salt industry was set over $50 \mathrm{mg} / \mathrm{kg}$, to ensure not less than $20 \mathrm{mg} / \mathrm{kg}$ when entering the household. With growing dual anxiety of iodine deficiency and iodine excess, what suitable level of fortification has been discussed and adjusted for several times. In 1996, $60 \mathrm{mg} / \mathrm{kg}$ was obliged as the maximum, and in 1997, the principle of scientific iodine supplement was put forward. Based on national urine iodine concentration (UIC) evaluation, especially in children or women [7] [8] [9], and other observations about thyroid function [10] [11], the iodization level was down regulated to $35 \pm 15 \mathrm{mg} / \mathrm{kg}$ in 2010 [12], and further narrowed to 14 - $39 \mathrm{mg} / \mathrm{kg}$ in 2011 version of National Standards on Food Safety-Iodine Content of Edible Salt [13]. According to local water iodine level, residents eating behavior and iodine nutritional status, provincial-level governments can make a decision to choose one of the three levels $(20,25,30 \mathrm{mg} / \mathrm{kg}$ salt) with $30 \%$ allowable variation range $(14-39 \mathrm{mg} / \mathrm{kg}$ salt $)$ as local salt iodiza- 
tion standard. Thus, China USI police have been gradually showing the trend of multiple iodization levels in one country, that is a little different from other countries or areas [14]. With more than two decades of consistent effort, China becomes the world's largest contributor for eliminating IDD. Along with the adjustment of salt iodization, the iodine status in the general population, proxied by median urine iodine concentration (UIC) in school age children, was shifted from insufficient baseline to more than adequate $(306.0 \mathrm{mg} / \mathrm{L})$ and back to adequate $(197.9 \mathrm{mg} / \mathrm{L})$ with improved symmetry of the thyroid volume distribution [7] [15] [16] [17].

Besides households salt, salt from manufactured foods including bread, meat, cheese, fast and ready to eat foods also constitutes the major share of the salt intake. Even in low- and middle-income areas, consumption of processed foods and condiments has been rising over the past few decades, influenced by income growth, urbanization, changing lifestyle practices and choices [18]. Recent changes in Asian food systems were proved to be driven by transnational food and beverage corporations in the retail, manufacturing and fast food sectors [19] [20]. Along with the improvement of food availability and accessibility, more and more Chinese people like to choose processed products, including pre-, semi- or ready-prepared foods, taking-out dishes in both urban and rural areas [21] [22]. Iodized salt used in China is not limited to home-made foods but also in commercially processed foods [3] [23], which something like iodine enrichment covers many kinds of foods. Analysis of iodine in processed foods has historically seldom been done until recently, to respond to changes in people's food choosing behavior and increasing anxiety about iodine deficiency and over-intake.

From 2017 to 2019, we completed the sample collection and iodine detection. Many reasons, like natural enrichment of iodine in food ingredients, the amount of total salt added, and the level of iodine fortified, make it a little difficult to evaluate the distribution of iodine content in variety of processed foods. We hope the work supply data for assessment of population iodine intake exposure, which may be useful for subsequent updating USI policy in the future.

\section{Materials and Method}

\subsection{Sample Collection}

From each of following municipality (Beijing), provincial capitals (Guangzhou, Hangzhou and Xining Heihe), prefecture-level city (Heihe), special economic zone (Shenzhen), and retail e-platforms (Tmall, Jingdong), commercial processed food samples, including cereal, tuber, legume, meat, fish, egg, and dairy products, and condiments, were randomly obtained from pedlars' markets and supermarkets during 2017 to 2019. According to sampling design, products consumed by volunteers who were involved in iodine intake investigation, and top selling products in particular with well-noted brands were preferentially selected. As to what salt is used, whether it contains iodine, and how much salt is added to products are related to enterprise's behavior, it's as far as possible to avoid re- 
peated sampling of products with same-brand, same type, even in different flavor. To represent overall iodine level, each sample for testing was homogenized mixture of 3 batches of samples from 3 markets, packed in polyethylene bottles and stored at $-20^{\circ} \mathrm{C}$. Each sample was given a unique laboratory number, and the sample details, including information marked on food label, like ingredients, nutrients facts, were logged into a database.

\subsection{Determination of Total Iodine Content}

Iodine content in each sample was pretreated with alkaline extraction and determined by ICP-MS at Chemical Laboratory of Shenzhen Center for Disease Control and Prevention. This method was proved to provide lower limits of quantification and higher accuracy [24], but in order to verify the results comparability, $10 \%$ samples were exchanged to National Reference Laboratory for Iodine Deficiency Disorders and checked the results by traditional method on basis of arsenic-cerium catalytic spectrophotometry, which already incorporated in National Food Safety Standard (GB 5009.267-2016) [25]. For quality control, all samples were analyzed in duplicate. Method blank and reference material sample (whole milk powder, SRM NIST 8435) were inserted in every 10 samples, $80 \%-120 \%$ iodine recovery and $<20 \%$ difference between replicates was requested. And additional $10 \%$ of samples were randomly rechecked to verify the results repeatability.

\subsection{Statistical Analysis}

The results were summarized based on steps showed in Figure 1. After merging samples with close iodine content in same style from same brand, and screening out samples with no added salt or low sodium content $(\leq 120 \mathrm{mg} / 100 \mathrm{~g})$, the iodine content existing in various kinds of food were expressed as medium with the range of minimum to maximum. Due to distribution of iodine contents influenced greatly by the ingredient background, food flavour, and edible salt used, the results were further analyzed. In our previous study, it was found the $95^{\text {th }}$ percentiles $\left(\mathrm{P}_{95}\right)$ of iodine content distribution in refined cereals, tubers, legumes, vegetables, livestock and poultry meats, was lower than $£ 8 \mathrm{mg} / 100 \mathrm{~g}$, no matter they came from low or high water iodine areas [26]. Therefore, compiling with the minimum regulated ratio of iodine to sodium (I:Na), we divided these food products with iodine content $£ 8 \mathrm{mg} / 100 \mathrm{~g}$ into Zone $\mathrm{A}$, and products with iodine content $>8$ products into zone B. The percentage of sample number in Zone $B$, in some sense, representing iodine from iodized salt, was calculated. Because the iodine background from egg, dairy, and marine foods are rather high, and the ingredients composed in condiments are more complex, it was not easy to judge the iodine source of these products, whereas only medium was given, unless it did not over the minimum I:Na.

\section{Results}

In this study, iodine content in total 808 samples were determined, apart from 


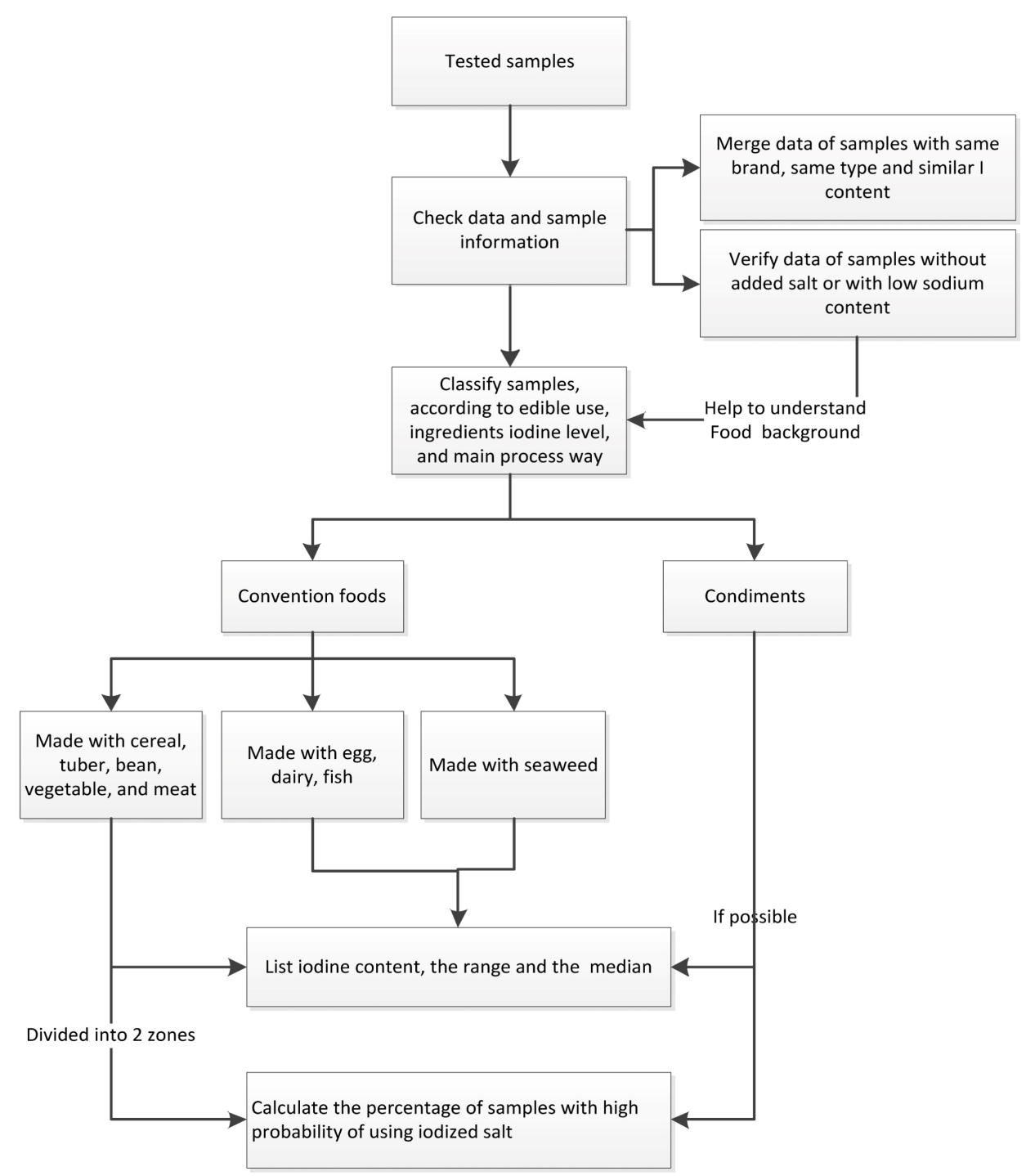

Figure 1. Scheme of processed food data analysis.

repeated samples and salt-free or low salt samples, total 725 data, among which 234 from grains, potatoes, beans, nuts, livestock and poultry meat products, 152 from egg, dairy, fish and seaweed, and 339 from condiments, were further sub-grouped and analyzed. As we had expected, the source of food ingredients, the amount of salt added and the usage of iodized salt was the main factors inducing large variation of iodine content in various foods. Iodine in salt-free or low salt samples helped us to understand its baseline from raw materials. Some Chinese traditional staple foods and bean curd products, like steamed bun (with or without sweeten red-bean pasty), starchy enema, lactone or marinated Tofu (fresh or dried), iodine varied from $<0.3 \mathrm{mg} / 100 \mathrm{~g}$ to $6.2 \mathrm{mg} / 100 \mathrm{~g}$. While, in yogurt, condensed milk, light butter, egg roll, custard pie and cake, the iodine was as high as $25.9 \mathrm{mg} / 100 \mathrm{~g}(4.7-190 \mathrm{mg} / 100 \mathrm{~g})$, although no or little salt was added. These results are consistent with routine variability presented in raw materials [26] [27]. 


\subsection{Iodine in Cereal, Tuber, Seed and Meat Products}

The range and median iodine level in salty products made from cereals, potatoes, legumes, nuts, and livestock and poultry meat, is showed in Table 1. Based on the numbers of samples fallen in Zone A and Zone B, we preliminarily understood that iodine in approximately $77 \%$ of the commercial food samples was from fortified salt. Cereals and tubers are important food source for human being. Noodle, pancake, dumpling, stuffed bun, and bread, are general considered as stable foods. Affected by palatability, the median sodium was mostly under 500 $\mathrm{mg} / 100 \mathrm{~g}$, and the median iodine content was among $7.6 \mathrm{mg} / 100 \mathrm{~g}$ to 25.8 $\mathrm{mg} / 100 \mathrm{~g}$.

In contrast, the sodium content in instant foods, leisure foods (such as puffed foods, spicy strips) seemed to be higher (medium, $663 \mathrm{mg} / 100 \mathrm{~g}$ to 2740 $\mathrm{mg} / 100 \mathrm{~g}$ ), resulting higher iodine content ranged between $39.8 \mathrm{mg} / 100 \mathrm{~g}$ to 149 $\mathrm{mg} / 100 \mathrm{~g}$ (medium). The medium of iodine in most bean curd products and meat products were about $40 \mathrm{mg} / 100 \mathrm{~g}(32.1 \mathrm{mg} / 100 \mathrm{~g}-44.3 \mathrm{mg} / 100 \mathrm{~g})$. Besides seasoning preparation, the needs of sodium in storage and the status of dehydration should be considered. There were also some extreme cases, such as fried nuts \& seeds, luncheon meat, which seemed mostly not use iodized salt. And others, like cured meat made by traditional Chinese way, appeared with high sodium and iodine value, but inevitably be lost, when cleaning, soaking and cooking happened before eating.

\subsection{Iodine in Egg, Dairy, Fish and Seaweed-Containing Products}

The data in Table 2 showed iodine content in egg, dairy, fish and seaweed containing products. Though the sampling number was a little small, the trends of iodine in products made from egg, cheese, fish were close to that in relevant raw materials, unless more salt was added. The distribution of iodine in seaweed containing products varied greatly, merely depending on the amount of seaweed added and itself variability. It is not easy to give a representative value for seaweed products, even it from same batch with same brand. We tried to give reliable data though repeated determination. The range of median iodine content for seasoned seaweed was $380 \mathrm{mg} / 100 \mathrm{~g}-2700 \mathrm{mg} / 100 \mathrm{~g}$, as to seaweed flavour products, like egg roll, biscuits, puffed foods, the medium was between 317 $\mathrm{mg} / 100 \mathrm{~g}$ to $649 \mathrm{mg} / 100 \mathrm{~g}$.

\subsection{Iodine in Condiments}

Seasonings are a kind of salty rich products, and the ingredients composed are more complex, making data analysis more difficult. 265 soy sauce with different style and different sodium from 83 factories were sampled and detected. Their medium of sodium values was $6720 \mathrm{mg} / 100 \mathrm{~g}(3140 \mathrm{mg} / 100 \mathrm{~g}-10,120 \mathrm{mg} / 100 \mathrm{~g})$. And the iodine contents were widely distributed, from below the detected limit to $896 \mathrm{mg} / 100 \mathrm{~g}$. We plotted frequency distribution histogram, from which, we found $74.7 \%(219 / 265)$ of samples were within the limit of iodine $<20 \mathrm{mg} / 100 \mathrm{~g}$, 
Table 1. Iodine contents in products made from cereal, tuber, bean and meat.

\begin{tabular}{|c|c|c|c|c|c|c|c|c|}
\hline \multirow{2}{*}{ Category } & \multirow{2}{*}{$\mathrm{n}$} & \multirow{2}{*}{$\begin{array}{c}\text { Labeled } \\
\text { sodium value } \\
(\mathrm{mg} / 100 \mathrm{~g})\end{array}$} & \multirow{2}{*}{$\begin{array}{l}\text { Iodine* }^{*} \\
(\mathrm{mg} / 100 \mathrm{~g})\end{array}$} & \multicolumn{2}{|c|}{ Zone $\mathrm{A}^{\star \#}$} & \multicolumn{2}{|c|}{ Zone $\mathrm{B}^{\star \#}$} & \multirow{2}{*}{ Note } \\
\hline & & & & $\mathrm{n}$ & Medium & $\mathrm{n}$ & Medium & \\
\hline Steamed roll & 2 & $288(198-378)$ & $12.0(11.9-12.9)$ & 0 & - & 2 & 12.0 & $\begin{array}{l}\text { Wheat made, } \\
\text { or glutinous rice with meat }\end{array}$ \\
\hline Pancake & 6 & $367(252-485)$ & $16.6(\operatorname{Tr}-23.4)$ & 1 & $\operatorname{Tr}$ & 5 & 17.4 & $\begin{array}{l}\text { Shredded, baked, } \\
\text { or with scallion }\end{array}$ \\
\hline Bread & 15 & $278(179-384)$ & $11.5(0.5-26.7)$ & 4 & 3.8 & 11 & 14.6 & Soft, hard, sliced, etc. \\
\hline Pastry & 8 & $321(196-606)$ & $18.4(13.7-32.8)$ & 0 & - & 8 & 18.4 & Sachima, peanut cake, etc. \\
\hline Biscuit & 28 & $350(224-749)$ & $7.6(0.2-51.9)$ & 15 & 4.0 & 13 & 14.6 & $\begin{array}{l}\text { Crispy, cookies, } \\
\text { sandwich biscuit, Wafer, } \\
\text { semi-hard biscuits, etc. }\end{array}$ \\
\hline $\begin{array}{c}\text { Dumpling \& } \\
\text { wonton, frozen }\end{array}$ & 15 & $424(296-785)$ & $14.2(0.6-105.7)$ & 4 & 6.0 & 11 & 16.7 & $\begin{array}{l}\text { With different kind of } \\
\text { vegetable and meat }\end{array}$ \\
\hline $\begin{array}{l}\text { Noodles, } \\
\text { semi-dried }\end{array}$ & 8 & $389(268-502)$ & $25.2(15.5-51.1)$ & 0 & - & 8 & 25.2 & $\begin{array}{l}\text { Hand pulled, shaved, } \\
\text { or home-made style }\end{array}$ \\
\hline Noodles, dried & 8 & $680(500-1700)$ & $25.8(2.3-34.3)$ & 2 & 3.3 & 6 & 27.2 & Vermicelli, sliced, ect. \\
\hline $\begin{array}{l}\text { Instant noodles, } \\
\text { with salt and } \\
\text { seasoning bag }\end{array}$ & 8 & $2200(1015-3005)$ & $101.9(50.7-313)$ & 0 & - & 8 & 101.9 & Wheat noodle, rice noodle \\
\hline Ready meal & 4 & $300(210-405)$ & $6.6(2.4-15.7)$ & 2 & 2.8 & 2 & 12.9 & Heat before eating \\
\hline Spicy gluten rich strip & 4 & $2740(2400-3290)$ & $149(141-171)$ & 0 & - & 4 & 149 & \\
\hline Puffed foods & 10 & $667(440-755)$ & $39.8(19.6-117)$ & 0 & - & 10 & 39.8 & $\begin{array}{c}\text { Potato chips, rice crisps, } \\
\text { white crackers }\end{array}$ \\
\hline $\begin{array}{l}\text { Dried or sliced } \\
\text { bean curds }\end{array}$ & 13 & $724(217-1344)$ & $36.9(0.8-142)$ & 4 & 2.3 & 9 & 53.0 & \\
\hline Fried Nuts \& seeds & 12 & $663(140-827)$ & $1.1(\operatorname{Tr}-221)$ & 9 & 0.6 & 3 & 142 & $\begin{array}{l}\text { Sunflower \& melon seeds, } \\
\text { peanuts, cashew-nuts, } \\
\text { almonds, dried green bean }\end{array}$ \\
\hline Sausage & 18 & $990(732-1300)$ & $41.7(20.7-112)$ & 0 & - & 18 & 41.7 & $\begin{array}{l}\text { Braised, roasted, garlic flavor } \\
\text { sausage, hot dog, etc. }\end{array}$ \\
\hline Ham or ham sausage & 19 & $1100(866-1100)$ & $44.1(28.5-62.4)$ & 0 & - & 19 & 44.1 & \\
\hline Bacon & 3 & $990(882-965)$ & $32.1(27.9-53.0)$ & & & 3 & 32.1 & \\
\hline Luncheon meat & 3 & $799(475-994)$ & $2.9(2.6-8.4)$ & 3 & 2.9 & 0 & - & \\
\hline Broiled meat & 12 & $859(600-1150)$ & $36.8(\operatorname{Tr}-99.6)$ & 2 & $\operatorname{Tr}$ & 10 & 46.2 & $\begin{array}{c}\text { Roasted Chick, pork, } \\
\text { beef, lamb, sauce duck, etc }\end{array}$ \\
\hline Pre-made meat & 9 & $690(475-900)$ & $10.1(1.4-19.5)$ & 3 & 1.4 & 6 & 10.9 & Steak, pork chop, chicken, etc, \\
\hline $\begin{array}{c}\text { Traditional } \\
\text { way dried } \\
\text { cured pork meat }\end{array}$ & 8 & $1751(1269-2485)$ & $125(1.8-170)$ & 3 & 1.9 & 5 & 128 & $\begin{array}{c}\text { Guangdong, Sichuan, } \\
\text { Hunan style, } \\
\text { clean \& cook before eating }\end{array}$ \\
\hline Sauce meat & 13 & $1170(840-1756)$ & $44.3(31.2-143)$ & 0 & - & 13 & 44.3 & Beef, pork elbow, duck \\
\hline
\end{tabular}




\section{Continued}

\begin{tabular}{|c|c|c|c|c|c|c|c|}
\hline $\begin{array}{l}\text { Beef jerky, or other } \\
\text { dried preserved meat }\end{array}$ & 8 & $1170(767-1967)$ & $41.8(6.0-54.1)$ & 1 & 6.0 & 7 & 42.7 \\
\hline total & 234 & & & 53 & & 181 & \\
\hline
\end{tabular}

${ }^{\star} \operatorname{Tr}$ : Content lower than detection limit $(0.3 \mu \mathrm{g} / 100 \mathrm{~g}) .{ }^{*}$-: No value.

Table 2. Iodine content in eggs, dairy and fish products and seaweed-containing foods.

\begin{tabular}{|c|c|c|c|c|}
\hline \multirow{2}{*}{ Category } & \multirow{2}{*}{$\mathrm{n}$} & \multirow{2}{*}{$\begin{array}{l}\text { labeled sodium value } \\
\qquad(\mathrm{mg} / 100 \mathrm{~g})\end{array}$} & \multicolumn{2}{|c|}{ Iodine content $(\mathrm{mg} / 100 \mathrm{~g})$} \\
\hline & & & Medium & Range \\
\hline Cheese & 3 & $1283(1080-1324)$ & 12.8 & $4.8-13.1$ \\
\hline Egg, pot-roast & 3 & $711(660-731)$ & 48.4 & $47.8-66.4$ \\
\hline Egg, preserved & 2 & 810 & 39.4 & $38.7-40.1$ \\
\hline Egg, salty & 3 & $2018(1763-2706)$ & 86.8 & $76.3-153$ \\
\hline Fish, canned & 5 & $1276(713-4039)$ & 26.7 & $17.4-30.3$ \\
\hline Fish, grilled, balled & 2 & 994 & 57.2 & $46.4-67.9$ \\
\hline Seaweed, seasoned & 7 & $1490(380-2700)$ & 1800 & $744-5875$ \\
\hline egg roll, with Seaweed & 12 & $317(174-477)$ & 83.6 & $30.1-136$ \\
\hline Biscuits, with Seaweed & 27 & $485(216-1142)$ & 59.0 & $10.4-246$ \\
\hline Pastry, with Seaweed & 5 & $321(198-830)$ & 48.7 & $30.1-95.8$ \\
\hline Puffed foods, with Seaweed & 83 & $649(140-2240)$ & 56.7 & $2.9-903$ \\
\hline
\end{tabular}

and the remaining floated from $100 \mathrm{mg} / 100 \mathrm{~g}$ to $700 \mathrm{mg} / 100 \mathrm{~g}$ (Figure 2). The ratio of I: Na helped to speculate that nearly $90 \%$ of soy sauce was not be added iodized salt, thus the overall medium of iodine was $4.0 \mathrm{mg} / 100 \mathrm{~g}$. Table 3 listed iodine in other condiments, about $73.5 \%$ (61/83) products was fallen in zone A. The median iodine content in most products was lower than $12 \mathrm{mg} / 100 \mathrm{~g}$, except Chili paste, as high as $105 \mathrm{mg} / 100 \mathrm{~g}$.

\section{Discussion}

As we know, many organism species cannot synthesize iodine by themselves, especially terrestrial organisms. They must take and absorb iodine from soil and water and others in the environment to enrich themselves. Next, they become iodine source of downstream food chain. Affected by geographical environment, growth cycle of animal and plant etc., the amount of iodine in foods can be highly variable, and the nature and degree of this variability can have implications for the complexity and cost of developing databases of iodine content [28] [29]. And, it is necessary to follow strict steps from sampling plans to data compiling, and confirm the stability of the analytes in both new and archived analytical samples. When analyzing population food composition or assessing iodine intake, evaluation of food iodine content variation with its impact on human 
Table 3. The iodine content in condiments.

\begin{tabular}{|c|c|c|c|c|c|c|c|}
\hline \multirow{2}{*}{ Condiments } & \multirow{2}{*}{$\mathrm{n}$} & \multirow{2}{*}{$\begin{array}{l}\text { labeled sodium value } \\
\qquad(\mathrm{mg} / 100 \mathrm{~g})\end{array}$} & \multirow{2}{*}{$\begin{array}{l}\text { Iodine content } \\
(\mathrm{mg} / 100 \mathrm{~g})\end{array}$} & \multicolumn{2}{|c|}{ Zone A } & \multicolumn{2}{|c|}{ Zone B } \\
\hline & & & & $\mathrm{n}$ & Medium & $\mathrm{n}$ & Medium \\
\hline Vinegar* & 11 & l & $11.3(1.3-41.6)$ & 6 & 3.6 & 5 & 26.7 \\
\hline Cooking wine ${ }^{\star}$ & 5 & I & $3.6(1.4-37.0)$ & 3 & 1.5 & 2 & 36.0 \\
\hline Oyster sauce & 7 & $4520(4367-5447)$ & $9.8(2.9-17.9)$ & 7 & 9.8 & 0 & - \\
\hline Bean paste/fermented soya beans & 5 & $4660(2340-11,000)$ & $5.1(0.7-60.9)$ & 3 & 2.1 & 2 & 57.6 \\
\hline Fermented bean curd & 7 & $3490(3000-4130)$ & $2.1(0.1-3.7)$ & 7 & 2.1 & 0 & - \\
\hline Chili paste & 5 & $3500(2541-4223)$ & $105(8.0-278)$ & 1 & - & 4 & 127 \\
\hline Salad paste & 4 & $798(618-1196)$ & $2.3(1.1-5.6)$ & 4 & 2.3 & 0 & - \\
\hline Sauce & 8 & $3994(1560-5333)$ & $7.9(2.4-202)$ & 5 & 2.6 & 3 & 198 \\
\hline Chicken essence (flavoring) & 9 & $20,000(18,000-22,020)$ & $9.5(4.9-1865)$ & 6 & 7.4 & 3 & 725 \\
\hline Hot pot base & 3 & $5798(5050-6546)$ & $10.7(0.3-30.8)$ & 1 & 0.3 & 2 & 20.7 \\
\hline Pickle & 19 & $1841(520-6280)$ & $4.2(0.9-214)$ & 16 & 3.4 & 3 & 100 \\
\hline Total & 83 & & & 61 & & 22 & \\
\hline
\end{tabular}

*exempted from labeling, because daily consumption less than $10 \mathrm{~g}(\mathrm{ml})$.

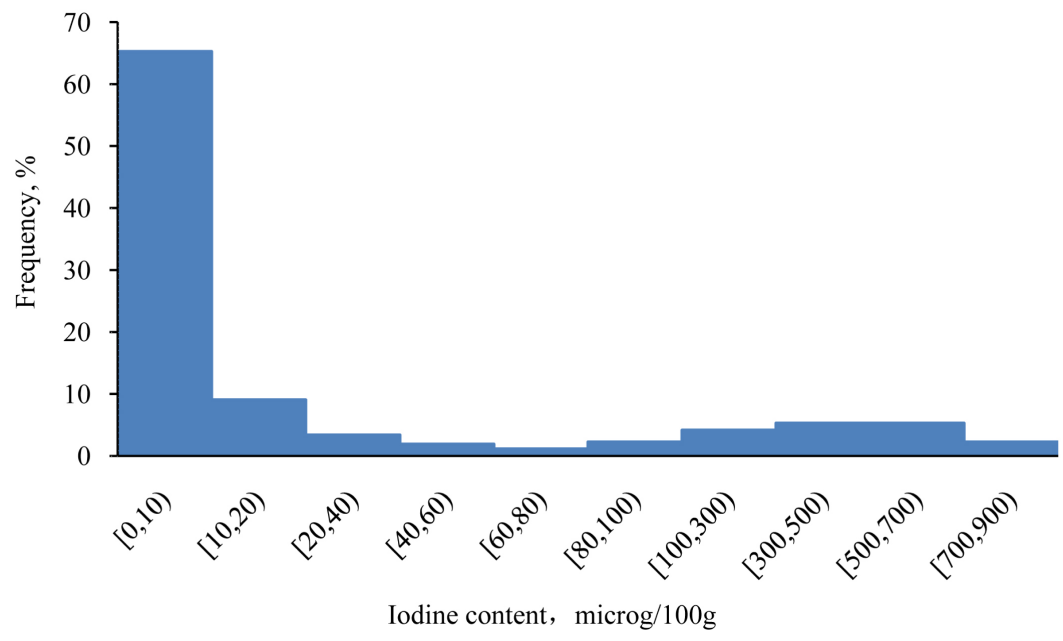

Figure 2. Frequency distribution of Iodine content in soy sauce.

iodine intake should be explored [30]. Different from some components, which are mostly expressed as average or medium value, highly variable and nonnormal (skewed) distributions of iodine content make it best presented by descriptive statistics that include multiple indicators of central tendency and range. Comprehensive databases on iodine in foods and dietary supplements have been developed in many countries, and compiled for calculation iodine intake [31]. In the newest version of China Food Composition Tables (standard edition), iodine content in samples collected from different water level areas has also been published [32]. 
The great variability existed in food iodine content, depending on the abundance of iodine in the local environment, might bring anxiety about overestimation or underestimation of iodine intake, and lead to obstacles to the understanding of the relationship between iodine fortification (or supplementation) and health. Well, in fact, according to risk assessment of iodine status in Chinese population, despite eggs, seafoods, and seaweed products are rich sources of dietary iodine, and cereals, vegetables and terrestrial animal meat can also supply part of iodine, iodized salt contributes most to iodine supply [33]. USI, defined as iodization of all food-grade salt used in the household, by food processing industries and for animal feed, is globally accepted as the most cost-effective public heath strategy to prevent and control IDD. The food industry's potential contribution to dietary intake through the use of iodized salt in food processing is significant and of growing importance. However, in many countries, food industry salt has not been a major focus of national USI strategies and, even where regulations exist, regulatory monitoring of food industry salt has not usually been practiced [23] [34]. In 2018, UNICEF released "UNICEF Guidance on the Monitoring of Salt Iodization Programmes and Determination of Population Iodine Status". To better understand overall USI programs, and where required, to revise iodization standards, the use of iodized salt in processed food and condiments should be considered, in particular, facing the change of salt consumption patterns. Some studies have tried to explore the strategy of using iodized salt in processed foods and the impact of iodine from processed foods on dietary intake. Through the results, international experience undertaken was reviewed [35], and potential iodine intake from industrial products was modelled according to the basic formula: quantity of salt per unit of food product $\times$ minimum regulated iodine level of salt at production $\times$ average daily per capita consumption of the product [23] [35] [36].

This paper, as far as we knew, is one of the few studies on the distribution of measured iodine content in processed foods and condiments, which mainly made in China. In order to eliminate IDD, a more widespread use of iodized salt, especially in industrially processed foods, has to be promoted. Well, correspondingly, both difficulties from iodine content variability caused by ingredients background, flavour, salt added amount, and regulated iodized level, and the uncertainty of each processed foods' consumption caused by difference among products, strengthen the challenges of iodine intake assessment. Taking into account food taste, shelf life, etc., commercial processed foods, in comparison with home-made foods or diets, are likely to have more salt or sodium from additives, that could induce higher iodine content, if iodized salt used, and the ratio of I:Na is not equal to ideal regulated value. As showed in this paper, the sodium content in fast and convenience food is higher than that of traditional unsalted staple foods. Even for same type of foods, the distance of sodium value at the first and the third quartile may be far apart [37]. With increasing economic and social development, more residents like to choose high protein food, prepackaged food or dine out home [38]. Quick-frozen dumplings, instant noodles, 
ready dishes, etc., with seasoning bags is entering dining table, and iodized salt used in food industry as a approach of USI have to make more and more contribution to the peoples' dietary iodine intake. A results from a urinary iodine and goiter monitoring in children aged 8 - 10 in Shanghai during 1997 and 2017 implicated that, though iodized salt consumption for home cooking in Shanghai has been declined, it has little effects on UIC and median thyroid volume, iodine from salt used in catering enterprises and food industry, prepackaged foods, most likely contribute to children iodine nutrition [39]. So, it is very important to establish an iodine database focused on processed foods and condiments, otherwise, whether underestimating or overestimating iodine intake, will affect assessment of iodine nutritional status. Permanent metabolic effects of excess iodine intake could occur if the iodine source is not detected and discontinued. Worry about excess iodine intake, and argument like excessive iodine intake and sub-clinical hypothyroidism in children and adolescents are also haunting many countries [19].

In facing social and environmental requirements of reducing chronic diseases, such as cardiovascular disease, salt reduction strategies are implemented world widely. In a report by the Global Action Plan for the Prevention and Control of Non-communicable Diseases (2013-2020), WHO has recommended a 30\% reduction in salt consumption worldwide [40]. This recommendation may be inconsistent with the current USI programs. In order to simultaneously push forward the two public health policies, ensuring that iodized salt has high penetration rate in food production and future monitoring of change in iodine nutrition from reduced salt use in processed foods and in households, in company with adjusting iodized salt fortification levels, is necessary [41] [42].

As the work of elimination of IDD gets deeper, more detailed measures need to be discussed and carried out, including but not limited to: 1) According to role of iodine intake, and the daily consumption of each food product in the dietary structure, establishing classified management rules for iodized salt application, to maximize the benefits under economic costs. For example, for products made from iodine-rich ingredients or products with low daily intake, it's no need or should be carefully to add iodized salt. Well, for foods that contribute a lot to the diet should balance the amount of salt added and the iodine fortified level. 2) Trying to complete food iodine labeling management, in compliant with FAO suggestion [43], if food containing added iodine. Till now, only salt is mandatory to be declared iodine content on labeling in China. In order to get knowledge about food iodine content by consumer and researcher in time, it's a good choice to mark iodine on food labeling. 3) Through education, advertisement and other forms, guiding the public skills to wisdom choose foods with suitable iodine to ensure their adequate intake for good health.

This study also comes with some limitations. Since the market is full of various processed food products with diverse types, multiple brands, and huge volume, this study could not use ideal random sampling methods. Therefore, the target samples were only selected on basis of volunteers' choice and market sur- 
vey results.

The results could not represent the overall iodine content in all types of products, but not affect the follow-up iodine intake survey.

\section{Conclusion}

Using iodized salt in processed foods is a skill of USI police. Affected by the nature backgrounds of ingredients composed, the amount of salt used, and the regulated fortification level, iodine content in each kind of product varied largely. In order to explore the iodine intake patterns and to develop appropriate strategic measures, it is necessary to describe and timely monitor the characteristics of dietary iodine sources. And for that, it's important to establish a national level monitoring system and iodine database, which will serve as an information source for understanding and analyzing the causes of iodine nutrition drifting, with its health benefit and risk.

\section{Acknowledgements}

We are grateful to Huimin Zhang from Centers for Disease Control and Prevention of Shenzhen, who helped us to finish the sample analysis. Grateful also give to Suying Chang, the nutrition specialist from the UNICEF (China), who often gave us suggestion.

\section{Funding}

This study was financially supported by both National Health Commission of PRC and UNICEF (China). The output data was used in projects The Risk Assessment of Iodine Status in Chinese Population, and Study of the effect of iodized salt utilization in processed foods and in eating out on the iodine intakes in Chinese residents. None of the above funder played a role in the study design, data analysis, or manuscript preparation.

\section{Conflicts of Interest}

The authors declare no conflicts of interest regarding the publication of this paper.

\section{Authors' Contributions}

Co-first authors, Z Wang, wzhblue@163.com, project executor and data interpreter; J Wang, junwangwh@hotmail.com, data compiler.

Correspondent author, XG Yang, xgyangcdc@vip.sina.com, project leader.

Other authors, WS Xu, GD Wang, J Zhao, sample collectors; J Xu, and X Li, chemical detector.

All authors read and approved the final manuscript.

\section{References}

[1] UNICEF (2008) Sustainable Elimination of Iodine Deficiency: Progress since the 1990 World Summit for Children. New York. 
[2] WHO (2007) Assessment of Iodine Deficiency Disorders and Monitoring Their Elimination: A Guide for Programme Managers, Third Edition. Geneva.

[3] Codling, K., Rudert, C., Bégin, F. and Peña-Rosas, J.P. (2017) The Legislative Framework for Salt Iodization in Asia and the Pacific and Its Impact on Programme Implementation. Public Health Nutrition, 20, 3008-3018. https://doi.org/10.1017/S1368980017001689

[4] Wang, J., Harris, M., Amos, B., Li, M., Wang, X., Zhang, J. and Chen, J. (1997) A Ten Year Review of the Iodine Deficiency Disorders Program of the People's Republic of China. The Journal of Public Health Policy, 18, 219-241. https://doi.org/10.2307/3343436

[5] Yan, Y.Q. (1995) Investigation of Iodine-Nutritional Status of School-Aged Children in 10 Big Cities of China. Chinese Journal of Control of Endemic Diseases, 10, 326-329, 383.

[6] The State Council of the People's Republic of China (1994) The Salt Industry Management Regulations for IDD (No. 163). SCPRC, Beijing.

[7] Chao, H., Zhang, Y.F., Liu, P., Han, Y.F. and Liu, SJ. (2016) Relationship between Iodine Content in Household Iodized Salt and Thyroid Volume Distribution in Children. Biomedical and Environmental Sciences, 29, 391-397.

[8] Gao, M., Chen, W., Sun, H., Fan, L., Wang, W., Du C., Chen, Y., Lin, L., Pearce, E.N. Shen, J., Cheng, Y., Wang, C. and Zhang, W. (2019) Excessive Iodine Intake Is Associated with Formation of Thyroid Nodules in Pregnant Chinese Women. $\mathrm{Nu}$ trition Research, 66, 61-67. https://doi.org/10.1016/j.nutres.2019.02.009

[9] National Iodine Deficiency Disorder Surveillance Group (2000) An Analysis and Report of China National Iodine Deficiency Disorders Surveillance Data in 1999. Chinese Journal of Control of Endemic Diseases, 19, 269-271.

[10] Kang, M.J., Hwang, I.T. and Chung, H.R. (2018) Excessive Iodine Intake and Subclinical Hypothyroidism in Children and Adolescents Aged 6-19 Years: Results of the Sixth Korean National Health and Nutrition Examination Survey, 2013-2015. Thyroid, 28, 773-779. https://doi.org/10.1089/thy.2017.0507

[11] Li, Y., Teng, D., Ba, J., Chen, B., Du J., He, L., Lai, X., Teng, X., Shi, X., Li, Y., Chi, H., Liao, E., Liu, C., Liu, L., Qin, G., Qin, Y., Quan, H., Shi, B., Sun, H., Tang, X., Tong, N., Wang, G., Zhang, J. A., Wang, Y., Xue, Y., Yan, L., Yang, J., Yang, L., Yao, Y., Ye, Z., Zhang, Q. and Zhang, L. (2020) Efficacy and Safety of Long-Term Universal Salt Iodization on Thyroid Disorders: Epidemiological Evidence from 31 Provinces of Mainland China. Thyroid, 30, 568-579.

https://doi.org/10.1089/thy.2019.0067

[12] The State Bureau of Quality and Technical Supervision (2000) National Standard: Edible Salt. GB 5461-2000. (In Chinese)

[13] Ministry of Health of the People's Republic of China (2011) National Food Safety Standard: Iodine Content in Edible Salt. GB 26878-2011. (In Chinese)

[14] Sun, D., Codling, K., Chang, S., Zhang, S., Shen, H., Su, X., Chen, Z., Scherpbier, R.W. and Yan, J. (2017) Eliminating Iodine Deficiency in China: Achievements, Challenges and Global IMPLICATIONS. Nutrients, 9, 361. https://doi.org/10.3390/nu9040361

[15] The Iodine Global Network (2015) Global Scorecard 2014: Number of Iodine Deficient Countries More than Halved in Past Decade.

[16] The Iodine Global Network (2019) Global Scorecard of Iodine Nutrition in 2019 in the General Population Based on School-Age Children (SAC). IGN, Zurich.

[17] The Iodine Global Network (2021) Global Scorecard of Iodine Nutrition in 2020 in the General Population Based on School-Age Children (SAC). IGN, Ottawa. 
[18] Reardon, T., Tschirley, D., Liverpool-Tasie, L.S.O., Awokuse, T., Fanzo, J., Minten, B., Vos, R., Dolislager, M., Sauer, C., Dhar, R., Vargas, C., Lartey, A., Raza, A. and Popkin, B.M. (2021) The Processed Food Revolution in African Food Systems and the Double Burden of Malnutrition. Global Food Security, 28, Article ID: 100466. https://doi.org/10.1016/j.gfs.2020.100466

[19] Baker, P. and Friel, S. (2016) Food Systems Transformations, Ultra-Processed Food Markets and the Nutrition Transition in Asia. Global Health, 12, 80. https://doi.org/10.1186/s12992-016-0223-3

[20] Pingali, P. (2007) Westernization of Asian Diets and the Transformation of Food Systems: Implications for Research and Policy. Food Policy, 32, 281-298. https://doi.org/10.1016/j.foodpol.2006.08.001

[21] Zhang, J., Wang, Z., Du, W., Su, C., Zhang, J., Jiang, H., Huang, F., Jia, X., Ouyang, Y., Wang, Y., Li, L., Zhang, B. and Wang, H. (2018) Intake of Pre-Packaged Foods among Chinese Adults Aged 18-59 Years Old in 15 Provinces, 2015. Journal of Hygiene Research, 47, 183-187. (In Chinese)

[22] Chang, J. and Wang, Y. (2016) Comprehensive Report on the Monitoring of Nutrition and Health Status of Chinese Residents 2010-2013. Peking University Medical Press, Beijing. (In Chinese)

[23] Knowles, J., van der Haar, F., Shehata, M., Gerasimov, G., Bimo, B., Cavenagh, B., Maramag, C.C., Otico, E., Izwardy, D., Spohrer, R. and Garrett, G.S. (2017) Iodine Intake through Processed Food: Case Studies from Egypt, Indonesia, the Philippines, the Russian Federation and Ukraine, 2010-2015. Nutrients, 9, 797. https://doi.org/10.3390/nu9080797

[24] Todorov, T.I., Smith, T., Abdalla, A., Mapulanga, S., Holmes, P., Hamilton, M., Lewis, T. and McDonald, M. (2018) Comparison of ICP-MS and Spectrophotometry Methods for the Analysis of Iodine in 2013 US FDA Total Diet Study Samples. Food Analytical Methods, 11, 3211-3223. https://doi.org/10.1007/s12161-018-1301-3

[25] National Health and Family Planning Commission (China), State Food and Drug Administration (2011) National Food Safety Standard: Determination of Iodine in Foods. GB 26878-2011. (In Chinese)

[26] Wang, Z., Xu, J., Yang, J.-M., Li, X.-W., Xu, W.-S. and Wang, G.-D. (2020) Variation of Iodine Content in Main Foods from China. Acta Nutrimenta Sinica, 42, 442-448.

[27] van der Reijden, O.L., Galetti, V., Herter-Aeberli, I., Zimmermann, M.B., Zeder, C., Krzystek, A., Haldimann, M., Barmaz, A., Kreuzer, M., Berard, J. and Schlegel, P. (2019) Effects of Feed Iodine Concentrations and Milk Processing on Iodine Concentrations of Cows' Milk and Dairy Products, and Potential Impact on Iodine Intake in Swiss Adults. British Journal of Nutrition, 122, 172-185. https://doi.org/10.1017/S0007114519001041

[28] Ershow, A., Skeaff, S., Merkel, J. and Pehrsson, P. (2018) Development of Databases on Iodine in Foods and Dietary Supplements. Nutrients, 10, 100. https://doi.org/10.3390/nu10010100

[29] Greenfield, H. and Southgate, D.A.T. (1992) Food Composition Data: Production, Management and Use. Elsevier Science Publishers Ltd., Rome.

[30] Carriquiry, A.L., Spungen, J.H., Murphy, S.P., Pehrsson, P.R., Dwyer, J.T., Juan, W.-Y. and Wirtz, M.S. (2016) Variation in the Iodine Concentrations of Foods: Considerations for Dietary Assessment. The American Journal of Clinical Nutrition, 104, 877S-887S. https://doi.org/10.3945/ajcn.115.110353

[31] Carlsen, M.H. andersen, L.F., Dahl, L., Norberg, N. and Hjartåker, A. (2018) New Iodine Food Composition Database and Updated Calculations of Iodine Intake 
among Norwegians. Nutrients, 10, 930. https://doi.org/10.3390/nu10070930

[32] Yang, Y.-X. (2019) China Food Composition Tables, Standard Edition. Vol. 2. Peking University Medical Press, Being, 311-324.

[33] China National Center for Food Safety Risk Assessment (2010) Salt Iodization and Risk Assessment of Iodine Status in Chinese Population. (In Chinese) http://www.gov.cn/gzdt/att/att/site1/20100713/0019b90463ff0da6b35001.pdf

[34] WHO/ICCIDD/UNICEF (2007) Assessment of Iodine Deficiency Disorders and Monitoring Their Elimination: A Guide for Programme Managers. WHO, Geneva.

[35] Spohrer, R., Garrett, G.S., Timmer, A., Sankar, R., Kar, B., Rasool, F. and Locatelli-Rossi, L. (2012) Processed Foods as an Integral Part of Universal Salt Iodization Programs: A Review of Global Experience and Analyses of Bangladesh and Pakistan. Food and Nutrition Bulletin, 33, S272-S280. https://doi.org/10.1177/15648265120334S303

[36] Chotivichien, S., Chongchaithet, N., Aksornchu, P., Boonmongkol, N., Duangmusik, P., Knowles, J. and Sinawat, S. (2021) Assessment of the Contribution of Industrially Processed Foods to Salt and Iodine Intake in Thailand. PLoS ONE, 16, e0253590. https://doi.org/10.1371/journal.pone.0253590

[37] NINH. China CDC/CNS (2019) Guideline for Salt Reduction in Chinese Food Industry. People's Medical Publishing House Co. Ltd., Beijing. (In Chinese)

[38] Zang, J., Luo, B., Wang, Y., Zhu, Z., Wang, Z., He, X., Wang, W., Guo, Y., Chen, X., Wang, C., Guo, C., Zou, S., Jia, X. and Wu, F. (2018) Eating Out-of-Home in Adult Residents in Shanghai and the Nutritional Differences among Dining Places. $\mathrm{Nu}$ trients, 10, 951. https://doi.org/10.3390/nu10070951

[39] Wang, Z., Zang, J., Shi Z, Zhu, Z., Song, J., Zou, S., Jin, W., Jia, X., Guo, C. and Liu, S. (2019) Iodine Status of 8 to 10 Years Old Children within 20 Years Following Compulsory Salt Iodization Policy in Shanghai, China. Nutrition Journal, 18, 63. https://doi.org/10.1186/s12937-019-0491-x

[40] WHO (2013) Global Action Plan for the Prevention and Control of Noncommunicable Diseases (2013-2020). Geneva.

[41] Van der Haar, F., Knowles, J., Bukania, Z., Camara, B., Pandav, C.S., Mwai, J.M., Toure, N.K. and Yadav, K. (2018) New Statistical Approach to Apportion Dietary Sources of Iodine Intake: Findings from Kenya, Senegal and India. Nutrients, 10, 430. https://doi.org/10.3390/nu10040430

[42] Johner, S.A., Günther, A.L. and Remer, T. (2011) Current Trends of 24-h Urinary Iodine Excretion in German Schoolchildren and the Importance of Iodised Salt in Processed Foods. British Journal of Nutrition, 106, 1749-1756. https://doi.org/10.1017/S0007114511005502

[43] Trumbo, P.R. (2016) FDA Regulations Regarding Iodine Addition to Foods and Labeling of Foods Containing Added Iodine. The American Journal of Clinical Nutrition, 104, 864S-867S. https://doi.org/10.3945/ajcn.115.110338

\section{Abbreviations}

IDD: Iodine Deficiency Disorders; UIC: Urinary Iodine Concentration; UNICEF: United Nations Children's Fund; USI: Universal Salt Iodization; WHO: World Health Organization. 